\title{
Modulation of dendritic cell functions by viral IL-10 encoded by human cytomegalovirus
}

\author{
Selmir Avdic ${ }^{1}$, Brian P. McSharry and Barry Slobedman ${ }^{1,2}$ * \\ ' Human Cytomegalovirus Research Group, Discipline of Infectious Diseases and Immunology, University of Sydney, Camperdown, NSW, Australia \\ ${ }^{2}$ Centre for Virus Research, Westmead Millennium Institute, Westmead, NSW, Australia
}

\section{Edited by:}

Michael McVoy, Virginia

Commonwealth University, USA

Reviewed by:

Michael McVoy, Virginia

Commonwealth University, USA

Juliet Spencer, University of San

Francisco, USA

Peter A. Barry, University of California,

Davis, USA

\section{*Correspondence:}

Barry Slobedman, Human

Cytomegalovirus Research Group,

Discipline of Infectious Diseases and

Immunology, Charles Perkins Centre,

Building D17, Johns Hopkins Drive,

University of Sydney, Camperdown,

NSW 2006, Australia

e-mail: barry.slobedman@sydney.edu.au
Human cytomegalovirus (HCMV), a clinically important $\beta$-herpesvirus, is a master of evasion and modulation of the host immune system, including inhibition of a number of dendritic cell (DC) functions. DCs play a central role in co-ordination of the immune response against pathogens and any disturbance of DCs functions can result in a cascade effect on a range of immune cells. Recently, the HCMV gene UL111A, which encodes viral homologs of human interleukin 10, has been identified as a strong suppressor of a number of DCs functions. In this mini review, we focus on HCMV-encoded viral IL-10-mediated inhibitory effects on DCs and implications for the development of an effective HCMV vaccine.

Keywords: dendritic cells, cytomegalovirus, interleukin 10, immunomodulation, virus replication and latency

\section{HUMAN CYTOMEGALOVIRUS}

Human cytomegalovirus (HCMV) is a species-specific $\beta$-herpesvirus that infects a majority of the world's population. Primary HCMV infection in the immunocompetent host is generally asymptomatic, with a minority of persons experiencing HCMV induced mononucleosis. However, in immunocompromised patients, such as allogeneic stem cell and solid organ transplant recipients and HIV/AIDS patients, HCMV infection results in severe disease affecting multiple organs that can be fatal (Mocarski et al., 2013). Furthermore, HCMV is the most common viral congenital infection which can lead to permanent disability such as hearing loss, mental retardation, and neurological defects (Kenneson and Cannon, 2007).

Following primary infection, HCMV establishes a life-long latent infection within myeloid progenitor cells. These precursor cells can then differentiate into a number of immune cell types including, monocytes, macrophages and dendritic cells (DCs), that play a vital role in functions such as antigen presentation leading to pathogen control and clearance (Reeves and Sinclair, 2008). During latency the virus persists without detectable replication; however, HCMV periodically reactivates from latent infection, resulting in production and shedding of infectious virus, and this process is most clinically important in immunosuppressed patients, particularly in allogeneic stem cell and solid organ transplant recipients, in which reactivating virus is the major cause of serious disease.

Human cytomegalovirus consists of a large, double-stranded DNA genome that encodes a range of immunomodulatory genes which function to limit both innate and adaptive host immunity. Such functions are likely to contribute to the lifelong persistence that follows primary infection that is characteristic of HCMV infection. In particular, HCMV encodes a number of soluble molecules that are homologs of host encoded cytokines and chemokines (McSharry et al., 2012). The best characterized of these proteins is the viral homolog of human IL-10 for which a range of immunomodulatory functions have been identified, and is the focus of this review.

\section{HCMV-ENCODED HOMOLOGS OF HUMAN INTERLEUKIN 10}

The human cytokine interleukin 10 (hIL-10) is a master regulator of the immune response, controlling functions of a number of different immune cell types (Moore et al., 2001). hIL-10 has particularly potent and varied effects on DCs. DC exposure to hIL-10 reduces their ability to activate and maintain immune responses, marked by suppression of pro-inflammatory cytokine production, expression of MHC class II and co-stimulatory molecules, DC maturation and ability to stimulate T cells (Hawrylowicz and O'Garra, 2005). The importance of IL-10 (either host cellular IL-10 or viral homologs of IL-10) in modulating DC function and controlling the anti-viral immune response is exemplified by the range of viruses infecting humans that either induce hIL-10 (e.g., HIV and hepatitis C virus; Reiser et al., 1997; Brockman et al., 2009) or encode their own homologs of this cytokine (e.g., Epstein Barr Virus and some cytomegaloviruses; Slobedman et al., 2009).

The HCMV gene UL111A encodes two viral homologs of human interleukin 10 (hIL-10); cmvIL-10 and LAcmvIL-10 that are both splice variants of the UL111A transcript. cmvIL-10 was identified first (Kotenko et al., 2000; Lockridge et al., 2000). This 
homolog shares only $27 \%$ amino acid identity with hIL-10, however, despite low homology with hIL-10, cmvIL-10 binds strongly and can signal through the hIL-10 receptor (Kotenko et al., 2000; Jones et al., 2002). LAcmvIL-10 is the second viral homolog of hIL-10 encoded by UL111A that has a truncated C-terminus due to alternative splicing (Jenkins etal., 2004), and together with cmvIL-10 makes up HCMV-encoded viral IL-10. Through intensive research activities of a number of groups over the last decade, a significant amount of data has been published demonstrating strong immunomodulatory functions of these viral IL-10 homologs on a range of human immune cells including DCs, monocytes, macrophages, and B cells (Spencer et al., 2002, 2008; Chang et al., 2004; Raftery et al., 2004; Yamamoto-Tabata et al., 2004; Jenkins et al., 2008; Cheung et al., 2009; Jaworowski et al., 2009; Slobedman et al., 2009; Avdic et al., 2011, 2013; McSharry et al., 2012). This review will principally focus on the effects of HCMV-encoded viral IL-10 on the function of DCs; cells often referred to as the sentinels of immunity, due to their exceptional ability to stimulate the immune response against pathogens.

\section{MODULATION BY HCMV-ENCODED HOMOLOGS OF hIL-10}

Dendritic cells play a central role in linking and co-ordination of the innate and adaptive immune responses against foreign antigens. The DC family can be broadly divided into classical DCs (cDCs) which are comprised of Langerhans cells (LC), myeloid DCs and plasmacytoid DCs (pDCs; Caux etal., 1996; Grouard et al., 1997; Merad et al., 2013). Upon antigen encounter, immature $\mathrm{cDCs}$ undergo the maturation process, where they migrate to lymph nodes, process and present antigens via MHC class I and class II to prime $\mathrm{CD}^{+}$and $\mathrm{CD}^{+}{ }^{+} \mathrm{T}$ lymphocytes, and also produce cytokines that further orchestrate an effective host immune response (De Smedt et al., 1996; Merad et al., 2013). Due to technological advances in flow cytometry and identification of novel cell surface markers over the last 10-15 years, new subsets of cDCs are continuing to be identified (Kim et al., 2014) and have been recently reviewed elsewhere (Merad et al., 2013). pDCs, on the other hand, represent a much smaller DC population that respond to initial viral stimuli primarily by strong production of the antiviral cytokine, interferon alpha (IFN- $\alpha)$, but also retain the ability to prime T cells (Colonna et al., 2004).

Human cytomegalovirus infection has been shown to involve direct interaction with DCs at a number of levels. Firstly, HCMV has been demonstrated to infect both immature and mature DCs in vitro (Jahn et al., 1999; Riegler et al., 2000; Moutaftsi et al., 2002; Hertel etal., 2003). Secondly, HCMV can latently infect DC precursors (Hahn etal., 1998) and DCs have been identified as a site of HCMV reactivation from natural latent infection (Reeves et al., 2005; Reeves and Sinclair, 2013). It therefore comes as little surprise that HCMV has developed multiple strategies to inhibit a range of DC functions with an ultimate goal of limiting or preventing virus clearance by the immune system. While some aspects of this multi-targeted approach of DC modulation by HCMV have been characterized (e.g., disturbance of MHC class I and class II antigen presenting pathways by products of HCMV genes US2-11; Jones et al., 1996; Wiertz et al., 1996; Ahn et al., 1997; Machold et al., 1997; Tomazin et al.,
1999), not all of HCMV-driven modulatory effects on DCs have been assigned to specific HCMV gene functions (Sinclair, 2008; Rolle and Olweus, 2009). However, it has become increasingly apparent that a number of DC functions are regulated by viral IL-10.

The first evidence of an HCMV-encoded IL-10 targeting DC function was reported by Peter Barry's group. Utilizing supernatants harvested from either infections with a UL111A deletion mutant virus or the parental (viral IL-10-expressing) HCMV strain, they identified that HCMV-encoded viral IL-10 plays an important role in regulating DC maturation (Chang et al., 2004). Indeed, progression of immature monocyte derived DCs (MDDCs), representing an in vitro model of cDC (Sallusto and Lanzavecchia, 1994), into the mature phenotype induced by lipopolysaccharide (LPS) was prevented by culture supernatants from cells infected with parent virus but not from supernatants from cells infected with the UL111A deletion mutant. Inhibition of DC maturation by cmvIL-10 protein is accompanied by suppression of pro-inflammatory cytokine synthesis by recombinant cmvIL-10 protein, whereas the LAcmvIL-10 protein did not exert this effect on DCs (Chang et al., 2004; Jenkins et al., 2008). Similarly, cmvIL-10 (but not LAcmvIL-10) suppresses a range of MDDC surface co-stimulatory molecules: CD80, CD83, CD86, and CD40, which are required for efficient $\mathrm{T}$ cell activation (Raftery et al., 2004; Jenkins et al., 2008). These studies not only demonstrated profound suppression of DC maturation by HCMV-encoded IL-10, but also highlighted a divergence in the functions of cmvIL-10 and LAcmvIL-10, showing that LAcmvIL-10 retains some (e.g., suppression of cell surface MHC class II complex expression required for antigen presentation to $\mathrm{CD}^{+} \mathrm{T}$ cells) but not all functions of cmvIL-10 (Jenkins et al., 2008).

In addition to limiting the ability of cmvIL-10 treated cDCs to efficiently stimulate immune responses, exposure of mature cDCs to cmvIL-10 (and hIL-10) also results in rapid cell apoptosis via suppressing the induction of anti-apoptotic genes $b c l-2, b c l-x$, and bfl-1 (Chang et al., 2007). Such effects are likely to limit the timeframe of antigen presentation and stimulation of T cells by cDCs exposed to cmvIL-10. A study by Raftery et al. (2004) similarly reported that cmvIL-10-induced $\mathrm{CDC}$ apoptosis in the presence of an inflammatory signal, which was linked to a reduction of antiapoptotic c-FLIP ${ }_{L}$ mRNA expression. This comprehensive study also reported several other mechanisms of cmvIL-10-driven control of cDC functions, including partial suppression of MHC class I and class II as well as co-stimulatory molecules B7-H1 and B7DC, ultimately resulting in suppressed ability of cmvIL-10-treated cDCs to induce proliferation of both allogeneic and autologous T cells (Raftery et al., 2004). Adding to this, cmvIL-10 also suppresses transcription of CD1 non-classical MHC class I molecules that are involved in presentation of lipids rather than peptides (Raftery et al., 2008).

Decreased cDC stimulatory activity is not due to suppression of antigen uptake by cmvIL-10-exposed cDCs. Rather, cmvIL-10 appears to actually stimulate antigen uptake in immature MDDCs (Raftery et al., 2004). This study also reported that surface expression of indoleamine 2,3-dioxygenase (IDO) was stimulated by cmvIL-10. IDO functions to suppress T cell responses by depletion 
of tryptophan (Hwu et al., 2000) and it has been suggested that IDO expressing cDCs may be involved in induction of $\mathrm{T}$ cell anergy (Munn et al., 2002). While it remains to be examined in an experimental setting, it is possible that increased antigen uptake by cmvIL-10-treated IDO expressing cDCs may lead to an increased proportion of HCMV antigens presented by $\mathrm{IDO}^{+}$ cDCs that could lead to an increased anergic role of anti-HCMV T cells.

The inhibitory effects of cmvIL-10 are not limited to cDC. cmvIL-10 released from HCMV-infected cells also effectively suppresses IFN- $\alpha$ mRNA transcription and protein synthesis by $\mathrm{pDCs}$ (Chang et al., 2009). This is biologically important in the context of HCMV infection as IFN- $\alpha$ stimulates other immune cells to clear the virus but also protects the same immune cells from HCMV infection (Chang et al., 2009).

Human cytomegalovirus establishes latent infection in $\mathrm{CD}_{3}{ }^{+}$ myeloid progenitors, which can differentiate into DCs or monocyte/macrophages. mRNA expression from the viral IL-10encoding HCMV gene UL111A has been detected during experimental as well as natural HCMV latent infection (Jenkins et al., 2004; Cheung etal., 2006), and work using UL111A deletion viruses has shown that $U L 111 A$ gene products suppress a number of immunostimulatory functions during HCMV latency. Firstly, surface MHC class II expression levels in myeloid progenitors latently infected with a parental, viral IL-10-expressing virus, are significantly lower than in progenitors infected with a UL111A deletion virus (Cheung et al., 2009). Consequently, stimulation of both allogeneic and autologous $\mathrm{CD} 4^{+} \mathrm{T}$ cell proliferation by progenitors carrying latent virus able to express viral IL-10 is notably suppressed compared to counterparts latently infected with the UL111A deletion virus (Cheung et al., 2009). Apart from their inability to prime $\mathrm{CD}^{+} \mathrm{T}$ cell responses, latently infected myeloid progenitors are also restricted by viral IL-10 in their ability to differentiate into myeloid DCs and LCs, with noted absence of pro-inflammatory cytokine expression by cells infected with the virus capable of expressing viral IL-10 (Avdic et al., 2011).

In addition to differentiation to DCs, myeloid progenitors can also differentiate into monocytes and macrophages which can act in antigen presenting roles. However, it appears that even these cells are impacted by viral IL-10, as exposure of these cells to viral IL-10 results in promotion of deactivated M2c monocytes/macrophages, rather than the classically activated, pro-inflammatory M1 type. This impact of viral IL-10 on monocyte/macrophage programming results in impairment of effective priming and proliferation of CD4 ${ }^{+} \mathrm{T}$ cells (Avdic et al., 2013).

Whilst viral IL-10 appears to minimize various DC functions required to instruct the immune system to clear the virus, this viral cytokine has also been reported to increase surface expression of DC-SIGN on immature MDDCs (Raftery et al., 2004). DC-SIGN is a lectin expressed on the cell surface of immature DCs and has been identified as a potential receptor for HCMV entry (Halary et al., 2002). Although it remains to be determined whether viral IL-10 plays any role in HCMV infection of DCs, it is possible that any viral IL-10mediated upregulation of DC-SIGN may enhance virus entry into DCs.

\section{BLOCKING VIRAL IL-10: POTENTIAL HCMV VACCINE STRATEGY}

The quest to develop a HCMV vaccine has been underway for $>40$ years (Elek and Stern, 1974). To this date, however, there is still no licensed HCMV vaccine. Multiple factors have complicated the development of an effective HCMV vaccine, with a significant limitation being the strict host specificity of HCMV, limiting the use of pre-clinical animal models to evaluate vaccine efficacy.

As already discussed, DCs are a critical component of the orchestrated immune response to pathogens that form a link between innate and adaptive immunity. For that reason, it is an imperative to ensure that DCs function at their best, instructing the immune system during initial response to vaccination and during subsequent challenge with live pathogens. Given that HCMV-encoded viral IL-10 severely alters DC functions, it could be argued that viral IL-10 expressed by any live attenuated HCMV vaccine candidate may limit the host's immune response toward such a vaccine. Indeed, several recent studies have investigated the role of viral IL-10 in the development of a vaccine against HCMV. Due to strict species specificity of HCMV, these studies have relied upon a rhesus macaque animal model, whereby rhesus monkeys are infected with rhesus CMV (RhCMV), which also encodes a viral IL-10. It is important to note that murine cytomegalovirus (MCMV) does not encode its own IL-10 homolog and this has limited the study of cytomegalovirus encoded IL-10 in more common animal models.

Two approaches have been utilized to investigate immune responses when the expression of viral IL-10 is blocked or modified. Firstly, it has been demonstrated that the blockade of RhCMV-encoded viral IL-10 expression (using a viral IL-10 knockout virus) during RhCMV infection in vivo resulted in a significant increase in DC numbers in draining lymph nodes and stronger $\mathrm{CD}^{+}{ }^{+} \mathrm{T}$ cell proliferation, as well as higher IgG titers (Chang and Barry, 2010). This study provided evidence that application of any live attenuated HCMV vaccine may be more effective at inducing anti-viral immunity if it contains targeted disruption of the viral IL-10 locus.

Secondly, it is known that antibodies are produced against viral IL-10 in both humans and rhesus macaques and that these can neutralize viral IL-10 function (de Lemos Rieper et al., 2011; Eberhardt et al., 2012). Therefore, blocking expression of viral IL-10 through gene deletion may limit a potential target of an effective immune response. An alternative approach to develop a vaccine whereby mutated versions of viral IL-10 unable to bind to the IL-10R but still able to stimulate production of anti-viral IL-10neutralizing antibodies has also been investigated. Immunization of seronegative animals with mutated forms of viral IL-10 prior to challenge with RhCMV resulted in decreased viral replication both locally (at the site of RhCMV infection) and systemically (with reduced viral shedding in bodily fluids; Logsdon et al., 2011; Eberhardt et al., 2013).

Collectively, these data demonstrate that abrogating the immunosuppressive functions of viral IL-10, whilst still enabling generation of anti-viral IL-10 antibody, may be an important component in the design of an effective vaccine against HCMV. 


\section{CONCLUSION}

Viral IL-10 encoded by HCMV UL111A employs a multi-targeted approach to profoundly modulate DC functions. It decreases DC differentiation from progenitor cells and DC maturation from immature DCs. Suppression of antigen presenting molecules (MHC class I and class II) together with suppression of costimulatory molecules both work together to reduce priming and proliferation of T cells. Additionally, viral IL-10 also suppresses secretion of pro-inflammatory cytokines, which is likely to add to repression of the immune response. Viral IL-10 can reduce the ability of DCs to present antigen via inhibition of anti-apoptotic factors but also potentially drives DCs toward a phenotype that could induce $\mathrm{T}$ cell anergy and therefore render the adaptive immune response less responsive to the virus infection. Together with other immunommodulatory genes encoded by HCMV, the impact of viral IL-10 on DCs is likely to create an environment that benefits the virus by limiting virus clearance by the host immune system.

\section{REFERENCES}

Ahn, K., Gruhler, A., Galocha, B., Jones, T. R., Wiertz, E. J., Ploegh, H. L., et al. (1997). The ER-luminal domain of the HCMV glycoprotein US6 inhibits peptide translocation by TAP. Immunity 6, 613-621. doi: 10.1016/S1074-7613(00) 80349-0

Avdic, S., Cao, J. Z., Cheung, A. K., Abendroth, A., and Slobedman, B. (2011). Viral interleukin-10 expressed by human cytomegalovirus during the latent phase of infection modulates latently infected myeloid cell differentiation. J. Virol. 85, 7465-7471. doi: 10.1128/JVI.00088-11

Avdic, S., Cao, J. Z., Mcsharry, B. P., Clancy, L. E., Brown, R., Steain, M., et al. (2013). Human cytomegalovirus interleukin-10 polarizes monocytes toward a deactivated M2c phenotype to repress host immune responses. J. Virol. 87, 10273 10282. doi: 10.1128/JVI.00912-13

Brockman, M. A., Kwon, D. S., Tighe, D. P., Pavlik, D. F., Rosato, P. C., Sela, J., et al. (2009). IL-10 is up-regulated in multiple cell types during viremic HIV infection and reversibly inhibits virus-specific T cells. Blood 114, 346-356. doi: 10.1182/blood-2008-12-191296

Caux, C., Vanbervliet, B., Massacrier, C., Dezutter-Dambuyant, C., De Saint-Vis, B., Jacquet, C., et al. (1996). CD34 ${ }^{+}$hematopoietic progenitors from human cord blood differentiate along two independent dendritic cell pathways in response to GM-CSF ${ }^{+}$TNF alpha. J. Exp. Med. 184, 695-706. doi: 10.1084/jem.184. 2.695

Chang, W. L., and Barry, P. A. (2010). Attenuation of innate immunity by cytomegalovirus IL-10 establishes a long-term deficit of adaptive antiviral immunity. Proc. Natl. Acad. Sci. U.S.A. 107, 22647-22652. doi: 10.1073/pnas.1013794108

Chang, W. L., Barry, P. A., Szubin, R., Wang, D., and Baumgarth, N. (2009). Human cytomegalovirus suppresses type I interferon secretion by plasmacytoid dendritic cells through its interleukin 10 homolog. Virology 390, 330-337. doi: 10.1016/j.virol.2009.05.013

Chang, W. L., Baumgarth, N., Eberhardt, M. K., Lee, C. Y., Baron, C. A., Gregg, J. P., et al. (2007). Exposure of myeloid dendritic cells to exogenous or endogenous IL-10 during maturation determines their longevity. J. Immunol. 178, 7794-7804. doi: 10.4049/jimmunol.178.12.7794

Chang, W. L., Baumgarth, N., Yu, D., and Barry, P. A. (2004). Human cytomegalovirus-encoded interleukin-10 homolog inhibits maturation of dendritic cells and alters their functionality. J. Virol. 78, 8720-8731. doi: 10.1128/JVI.78.16.8720-8731.2004

Cheung, A. K., Abendroth, A., Cunningham, A. L., and Slobedman, B. (2006). Viral gene expression during the establishment of human cytomegalovirus latent infection in myeloid progenitor cells. Blood 108, 3691-3699.

Cheung, A. K., Gottlieb, D. J., Plachter, B., Pepperl-Klindworth, S., Avdic, S., Cunningham, A. L., et al. (2009). The role of the human cytomegalovirus UL111A gene in downregulating $\mathrm{CD}^{+} \mathrm{T}$ cell recognition of latently infected cells: implications for virus elimination during latency. Blood 114, 4128-4137. doi: 10.1182/blood-2008-12-197111
Colonna, M., Trinchieri, G., and Liu, Y. J. (2004). Plasmacytoid dendritic cells in immunity. Nat. Immunol. 5, 1219-1226. doi: 10.1038/ni1141

de Lemos Rieper, C., Galle, P., Pedersen, B. K., and Hansen, M. B. (2011). Characterization of specific antibodies against cytomegalovirus (CMV)-encoded interleukin 10 produced by $28 \%$ of CMV-seropositive blood donors. J. Gen. Virol. 92, 1508-1518. doi: 10.1099/vir.0.028738-0

De Smedt, T., Pajak, B., Muraille, E., Lespagnard, L., Heinen, E., De Baetselier, P., et al. (1996). Regulation of dendritic cell numbers and maturation by lipopolysaccharide in vivo. J. Exp. Med. 184, 1413-1424. doi: 10.1084/jem.184.4.1413

Eberhardt, M. K., Chang, W. L., Logsdon, N. J., Yue, Y., Walter, M. R., and Barry, P. A. (2012). Host immune responses to a viral immune modulating protein: immunogenicity of viral interleukin-10 in rhesus cytomegalovirus-infected rhesus macaques. PLoS ONE 7:e37931. doi: 10.1371/journal.pone.0037931

Eberhardt, M. K., Deshpande, A., Chang, W. L., Barthold, S. W., Walter, M. R., and Barry, P. A. (2013). Vaccination against a virus-encoded cytokine significantly restricts viral challenge. J. Virol. 87, 11323-11331. doi: 10.1128/JVI.01925-13

Elek, S. D., and Stern, H. (1974). Development of a vaccine against mental retardation caused by cytomegalovirus infection in utero. Lancet 1, 1-5. doi: 10.1016/S0140-6736(74)92997-3

Grouard, G., Rissoan, M. C., Filgueira, L., Durand, I., Banchereau, J., and Liu, Y. J. (1997). The enigmatic plasmacytoid T cells develop into dendritic cells with interleukin (IL)-3 and CD40-ligand. J. Exp. Med. 185, 1101-1111. doi: 10.1084/jem.185.6.1101

Hahn, G., Jores, R., and Mocarski, E. S. (1998). Cytomegalovirus remains latent in a common precursor of dendritic and myeloid cells. Proc. Natl. Acad. Sci. U.S.A. 95, 3937-3942. doi: 10.1073/pnas.95.7.3937

Halary, F., Amara, A., Lortat-Jacob, H., Messerle, M., Delaunay, T., Houles, C., et al. (2002). Human cytomegalovirus binding to DC-SIGN is required for dendritic cell infection and target cell trans-infection. Immunity 17, 653-664. doi: 10.1016/S1074-7613(02)00447-8

Hawrylowicz, C. M., and O'Garra, A. (2005). Potential role of interleukin-10secreting regulatory $\mathrm{T}$ cells in allergy and asthma. Nat. Rev. Immunol. 5, 271-283. doi: 10.1038/nri1589

Hertel, L., Lacaille, V. G., Strobl, H., Mellins, E. D., and Mocarski, E. S. (2003). Susceptibility of immature and mature Langerhans cell-type dendritic cells to infection and immunomodulation by human cytomegalovirus. J. Virol. 77, 75637574. doi: 10.1128/JVI.77.13.7563-7574.2003

Hwu, P., Du, M. X., Lapointe, R., Do, M., Taylor, M. W., and Young, H. A. (2000). Indoleamine 2,3-dioxygenase production by human dendritic cells results in the inhibition of T cell proliferation. J. Immunol. 164, 3596-3599. doi: 10.4049/jimmunol.164.7.3596

Jahn, G., Stenglein, S., Riegler, S., Einsele, H., and Sinzger, C. (1999). Human cytomegalovirus infection of immature dendritic cells and macrophages. Intervirology 42, 365-372. doi: 10.1159/000053973

Jaworowski, A., Cheng, W. J., Westhorpe, C. L., Abendroth, A., Crowe, S. M., and Slobedman, B. (2009). Enhanced monocyte Fc phagocytosis by a homologue of interleukin-10 encoded by human cytomegalovirus. Virology 391, 20-24. doi: 10.1016/j.virol.2009.06.003

Jenkins, C., Abendroth, A., and Slobedman, B. (2004). A novel viral transcript with homology to human interleukin-10 is expressed during latent human cytomegalovirus infection. J. Virol. 78, 1440-1447. doi: 10.1128/JVI.78.3.14401447.2004

Jenkins, C., Garcia, W., Godwin, M. J., Spencer, J. V., Stern, J. L., Abendroth, A., et al. (2008). Immunomodulatory properties of a viral homolog of human interleukin-10 expressed by human cytomegalovirus during the latent phase of infection. J. Virol. 82, 3736-3750. doi: 10.1128/JVI.02173-07

Jones, B. C., Logsdon, N. J., Josephson, K., Cook, J., Barry, P. A., and Walter, M. R. (2002). Crystal structure of human cytomegalovirus IL-10 bound to soluble human IL-10R1. Proc. Natl. Acad. Sci. U.S.A. 99, 9404-9409. doi: 10.1073/pnas.152147499

Jones, T. R., Wiertz, E. J., Sun, L., Fish, K. N., Nelson, J. A., and Ploegh, H. L. (1996). Human cytomegalovirus US3 impairs transport and maturation of major histocompatibility complex class I heavy chains. Proc. Natl. Acad. Sci. U.S.A. 93, 11327-11333. doi: 10.1073/pnas.93.21.11327

Kenneson, A., and Cannon, M. J. (2007). Review and meta-analysis of the epidemiology of congenital cytomegalovirus (CMV) infection. Rev. Med. Virol. 17, 253-276. doi: 10.1002/rmv.535

Kim, T. S., Gorski, S. A., Hahn, S., Murphy, K. M., and Braciale, T. J. (2014). Distinct dendritic cell subsets dictate the fate decision between effector and memory 
CD8(+) T cell differentiation by a CD24-dependent mechanism. Immunity 40, 400-413. doi: 10.1016/j.immuni.2014.02.004

Kotenko, S. V., Saccani, S., Izotova, L. S., Mirochnitchenko, O. V., and Pestka, S. (2000). Human cytomegalovirus harbors its own unique IL-10 homolog (cmvIL-10). Proc. Natl. Acad. Sci. U.S.A. 97, 1695-1700. doi: 10.1073/pnas.97.4.1695

Lockridge, K. M., Zhou, S. S., Kravitz, R. H., Johnson, J. L., Sawai, E. T., Blewett, E. L., et al. (2000). Primate cytomegaloviruses encode and express an IL-10-like protein. Virology 268, 272-280. doi: 10.1006/viro.2000.0195

Logsdon, N. J., Eberhardt, M. K., Allen, C. E., Barry, P. A., and Walter, M. R. (2011). Design and analysis of rhesus cytomegalovirus IL-10 mutants as a model for novel vaccines against human cytomegalovirus. PLoS ONE 6:e28127. doi: 10.1371/journal.pone.0028127

Machold, R. P., Wiertz, E. J., Jones, T. R., and Ploegh, H. L. (1997). The HCMV gene products US11 and US2 differ in their ability to attack allelic forms of murine major histocompatibility complex (MHC) class I heavy chains. J. Exp. Med. 185, 363-366. doi: 10.1084/jem.185.2.363

McSharry, B. P., Avdic, S., and Slobedman, B. (2012). Human cytomegalovirus encoded homologs of cytokines, chemokines and their receptors: roles in immunomodulation. Viruses 4, 2448-2470. doi: 10.3390/v4112448

Merad, M., Sathe, P., Helft, J., Miller, J., and Mortha, A. (2013). The dendritic cell lineage: ontogeny and function of dendritic cells and their subsets in the steady state and the inflamed setting. Annu. Rev. Immunol. 31, 563-604. doi: 10.1146/annurev-immunol-020711-074950

Mocarski, E. S., Shenk, T., Griffiths, P. D., and Pass, R. F. (2013) "Cytomegaloviruses," in Fields Virology, 6th Edn, eds D. M. Knipe and P. M Howley (Philadelphia, PA: Wolters Kluwer/Lippincott Williams \& Wilkins), 1960-2014.

Moore, K. W., De Waal Malefyt, R., Coffman, R. L., and O'Garra, A. (2001). Interleukin-10 and the interleukin-10 receptor. Annu. Rev. Immunol. 19, 683-765. doi: 10.1146/annurev.immunol.19.1.683

Moutaftsi, M., Mehl, A. M., Borysiewicz, L. K., and Tabi, Z. (2002). Human cytomegalovirus inhibits maturation and impairs function of monocyte-derived dendritic cells. Blood 99, 2913-2921. doi: 10.1182/blood.V99.8.2913

Munn, D. H., Sharma, M. D., Lee, J. R., Jhaver, K. G., Johnson, T. S., Keskin, D. B., et al. (2002). Potential regulatory function of human dendritic cells expressing indoleamine 2,3-dioxygenase. Science 297, 1867-1870. doi $10.1126 /$ science. 1073514

Raftery, M. J., Hitzler, M., Winau, F., Giese, T., Plachter, B., Kaufmann, S. H., et al. (2008). Inhibition of CD1 antigen presentation by human cytomegalovirus. J. Virol. 82, 4308-4319. doi: 10.1128/JVI.01447-07

Raftery, M. J., Wieland, D., Gronewald, S., Kraus, A. A., Giese, T., and Schonrich, G. (2004). Shaping phenotype, function, and survival of dendritic cells by cytomegalovirus-encoded IL-10. J. Immunol. 173, 3383-3391. doi: 10.4049/jimmunol.173.5.3383

Reeves, M. B., Macary, P. A., Lehner, P. J., Sissons, J. G., and Sinclair, J. H. (2005). Latency, chromatin remodeling, and reactivation of human cytomegalovirus in the dendritic cells of healthy carriers. Proc. Natl. Acad. Sci. U.S.A. 102, 4140-4145. doi: 10.1073/pnas.0408994102

Reeves, M., and Sinclair, J. (2008). Aspects of human cytomegalovirus latency and reactivation. Curr. Top. Microbiol. Immunol. 325, 297-313. doi: 10.1007/978-3540-77349-8_17

Reeves, M. B., and Sinclair, J. H. (2013). Circulating dendritic cells isolated from healthy seropositive donors are sites of human cytomegalovirus reactivation in vivo. J. Virol. 87, 10660-10667. doi: 10.1128/JVI.01539-13
Reiser, M., Marousis, C. G., Nelson, D. R., Lauer, G., Gonzalez-Peralta, R. P., Davis, G. L., et al. (1997). Serum interleukin 4 and interleukin 10 levels in patients with chronic hepatitis C virus infection. J. Hepatol. 26, 471-478. doi: 10.1016/S01688278(97)80409-6

Riegler, S., Hebart, H., Einsele, H., Brossart, P., Jahn, G., and Sinzger, C. (2000). Monocyte-derived dendritic cells are permissive to the complete replicative cycle of human cytomegalovirus. J. Gen. Virol. 81, 393-399.

Rolle, A., and Olweus, J. (2009). Dendritic cells in cytomegalovirus infection: viral evasion and host countermeasures. APMIS 117, 413-426. doi: 10.1111/j.16000463.2009.02449.x

Sallusto, F., and Lanzavecchia, A. (1994). Efficient presentation of soluble antigen by cultured human dendritic cells is maintained by granulocyte/macrophage colony-stimulating factor plus interleukin 4 and downregulated by tumor necrosis factor alpha. J. Exp. Med. 179, 1109-1118. doi: 10.1084/jem.179. 4.1109

Sinclair, J. (2008). Manipulation of dendritic cell functions by human cytomegalovirus. Expert Rev. Mol. Med. 10:e35. doi: 10.1017/S1462399408000872 Slobedman, B., Barry, P. A., Spencer, J. V., Avdic, S., and Abendroth, A. (2009). Virus-encoded homologs of cellular interleukin-10 and their control of host immune function. J. Virol. 83, 9618-9629. doi: 10.1128/JVI. 01098-09

Spencer, J. V., Cadaoas, J., Castillo, P. R., Saini, V., and Slobedman, B. (2008). Stimulation of B lymphocytes by cmvIL-10 but not LAcmvIL-10. Virology 374, 164-169. doi: 10.1016/j.virol.2007.11.031

Spencer, J. V., Lockridge, K. M., Barry, P. A., Lin, G., Tsang, M., Penfold, M. E., et al. (2002). Potent immunosuppressive activities of cytomegalovirus-encoded interleukin-10. J. Virol. 76, 1285-1292. doi: 10.1128/JVI.76.3.1285-1292.2002

Tomazin, R., Boname, J., Hegde, N. R., Lewinsohn, D. M., Altschuler, Y., Jones, T. R., et al. (1999). Cytomegalovirus US2 destroys two components of the MHC class II pathway, preventing recognition by CD4+ T cells. Nat. Med. 5, 1039-1043. doi: $10.1038 / 12478$

Wiertz, E. J., Jones, T. R., Sun, L., Bogyo, M., Geuze, H. J., and Ploegh, H. L. (1996). The human cytomegalovirus US11 gene product dislocates MHC class I heavy chains from the endoplasmic reticulum to the cytosol. Cell 84, 769-779. doi: 10.1016/S0092-8674(00)81054-5

Yamamoto-Tabata, T., Mcdonagh, S., Chang, H. T., Fisher, S., and Pereira, L. (2004). Human cytomegalovirus interleukin-10 downregulates metalloproteinase activity and impairs endothelial cell migration and placental cytotrophoblast invasiveness in vitro. J. Virol. 78, 2831-2840. doi: 10.1128/JVI.78.6.2831-2840.2004

Conflict of Interest Statement: The authors declare that the research was conducted in the absence of any commercial or financial relationships that could be construed as a potential conflict of interest.

Received: 01 May 2014; accepted: 17 June 2014; published online: 04 July 2014.

Citation: Avdic S, McSharry BP and Slobedman B (2014) Modulation of dendritic cell functions by viral IL-10 encoded by human cytomegalovirus. Front. Microbiol. 5:337. doi: 10.3389/fmicb.2014.00337

This article was submitted to Virology, a section of the journal Frontiers in Microbiology. Copyright (c) 2014 Avdic, McSharry and Slobedman. This is an open-access article distributed under the terms of the Creative Commons Attribution License (CC BY). The use, distribution or reproduction in other forums is permitted, provided the original author(s) or licensor are credited and that the original publication in this journal is cited, in accordance with accepted academic practice. No use, distribution or reproduction is permitted which does not comply with these terms. 